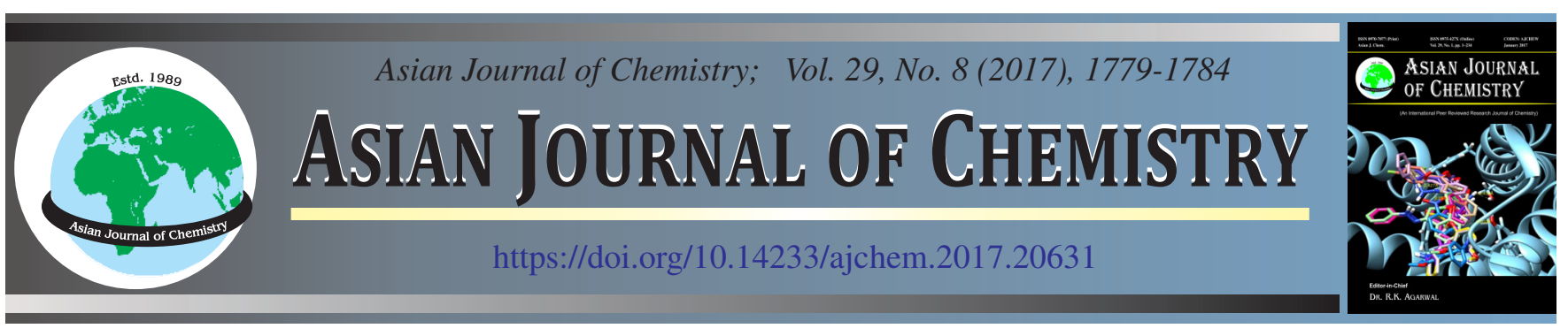

\title{
Effect of Organo-Nitrogen Compounds on Inhibition Efficiency of Mild Steel Corrosion in Acidic Media
}

\author{
Asma Mohammed Z. El-ShariF
}

Chemistry Department, University of Dammam, Dammam 31113, Saudi Arabia

Corresponding author: E-mail: aelsharif@uod.edu.sa \begin{abstract}
Some dodecylamine derivatives have been synthesized and were further elaborated by quaternization with an allyl group. The presence of diallyl moiety made some of these derivatives effective in inhibiting mild steel corrosion in acidic media. The study of mild steel corrosion was carried out using gravimetric and potentiodynamic polarization methods. At $60{ }^{\circ} \mathrm{C}$, the inhibitors exhibited excellent inhibition efficiencies (\% IE) of about $99 \%$ (at $200 \mathrm{ppm}$ ) in $1 \mathrm{M} \mathrm{HCl}$ and about 11-97 \% (at $400 \mathrm{ppm}$ ) in $0.5 \mathrm{M} \mathrm{H}_{2} \mathrm{SO}_{4}$. The inhibitors containing the diallyl moiety demonstrated the higher inhibition efficiencies in $\mathrm{H}_{2} \mathrm{SO}_{4}$. Some of the quaternary salts were effective in preventing corrosion in $3.5 \% \mathrm{NaCl}$ (\% IE about $63-85 \%$ at $200 \mathrm{ppm}$ ). The coordinate type of bond involving interactions of $\pi$-electrons with the iron $d$-orbitals allows the inhibitors to impede anodic oxidation of iron. The mechanisms emphasizing the role of the synthesized organonitrogen moieties in corrosion suppression process.
\end{abstract}

Keywords: Corrosion inhibition, Mild steel, Acidic media, Saline media, Polarization curves, Dodecyl amines.

\section{INTRODUCTION}

To protect metals from corrosion, a number of methods are being used namely cathodic protection, anodic protection, galvanization, organic coatings, inorganic coatings, ceramic/glass lining and addition of inhibitors. Inhibitors are mixed in a small quantity to the corrosive environment (often liquid and sometimes vapour) to reduce the rate of corrosion. The inhibitors can suppress the anodic, the cathodic or both electrochemical reactions. The efficiency of an inhibitor can be compared by comparing anodic and cathodic polarization curves and by comparing the corrosion rates estimated from corrosion current [1-3].

Corrosion inhibitors, when added to a system, are adsorbed at the metal solution interface. The nature of the chemical structure of the inhibitor and the residual charge on the surface of the metal control the adsorption. The organic inhibitors are adsorbed on the metal surface either by physical adsorption or electrostatic and chemisorption $[4,5]$.

Chemisorption, however, involves strong interaction between the metal surface and an inhibitor molecule. A coordinate covalent bond involving transfer of electron from inhibitor to the metal surface is formed [6]. Functional group with donor atoms having unshared lone pairs, transfer electron to the metal surface. Availability of $\pi$-electrons in inhibitor containing multiple bonds or aromatic rings also facilitates electron transfer from the inhibitor to the metal. The strength of the chemisorption bond depends upon the electron density on donor atom of the functional group and the polarizability of the group [7-9]. During the last decade, a number of papers correlating chemical structure of the substances and its inhibiting action have appeared [10].

The organic compounds containing heteroatoms $(\mathrm{N}, \mathrm{O}$, $\mathrm{P}, \mathrm{S}$, etc.) are widely used inhibitors of corrosion of mild steel under various corrosive environments [1,11-14]. The cationic nitrogen compounds are efficient inhibitors in $\mathrm{HCl}$ but fail to impart good inhibition efficacy in sulfuric acid media. The inhibitors may undergo physisorption on the metal surface [15], or chemisorption by non-bonded- and $\pi$-electrons of the organic inhibitors with the vacant $d$-orbitals of the iron [16]. The compounds containing alkyne moieties are good inhibitors as it could polymerized on the metal surface thus giving a protective coat of a polymer film $[17,18]$.

The surface charge of iron is positive in both $\mathrm{H}_{2} \mathrm{SO}_{4}$ and $\mathrm{HCl}$; repulsive forces do no encourage the adsorption of inhibitor cations $\left(\mathrm{Inh}^{+}\right)$. The chloride ions are adsorbed more strongly on the metal surface than the sulfate ions [19]. This will lead to easier and favoured formation of $\left(\mathrm{FeCl}^{-} \cdots \mathrm{Inh}^{+}\right)_{\mathrm{ad}}$. The lesser adsorbability of sulfate ions may lead to lower inhibition efficiency as a result of difficulty in the formation of the species $\left(\mathrm{FeSO}_{4}^{-} \cdots \mathrm{Inh}^{+}\right)_{\text {ad }}$ on the metal surface [20]. The inhibitors having the ability to impart mild steel corrosion inhibition in both the acidic media are not much common. 
Organic adsorption inhibitors usually coat metal with an oily surface layer to protect the metal. Organic inhibitors can be used in acidic, neutral and alkaline solutions. They displace water molecule from the metal surface and thus prevent solvation of metal ions by water and also prevent $\mathrm{H}^{+}$ions from cathode sites where reduction to $\mathrm{H}_{2}$ could take place.

Electrostatic attraction between organic ions or dipoles and the electrically charged metallic surface may lead to physical adsorption. However, charge transfer or covalent bonding may lead to chemisorption.

A suitable organic inhibitor must have a functionality that could impart dipole or ionic charge in the molecule. Such functionality could be aliphatic, aromatic or heterocyclic amines, quaternary ammonium compounds, triazoles [21], thiocarbamide, sulfoxides, marcaptans, sulfides, a double or a triple bond in a long hydrocarbon chain [22]. Increasing the length of the hydrocarbon chain decreases the solubility of the amine inhibitors.

In the present work, we examined the effects of substituents and functional groups present in derivatives of dodecyl amines on the inhibition of mild steel corrosion in several corrosive media. The incorporation of multiple functional groups within the molecule would help the inhibitor to lock on the metal surface better with minimum chance of getting out of the metal surface.

\section{EXPERIMENTAL}

Propargyl chloride, pyrrolidine, allyl chloride, etc. were purchased from Fluka Chemie AG (Buchs, Switzerland).

${ }^{1} \mathrm{H}$ and ${ }^{13} \mathrm{C}$ spectra were measured on a JEOL LA 500 $\mathrm{MHz}$ NMR spectrometer (using solvent $\mathrm{CDCl}_{3}$ and internal standard TMS). All the reactions were carried out under $\mathrm{N}_{2}$. Newly synthesized compounds gave satisfactory elemental analyses (on a Carlo-Erba Model 1106).

Distilled deionized water, concentrated $\mathrm{HCl}$ (A.C.S), $\mathrm{H}_{2} \mathrm{SO}_{4}$ (Fisher Scientific Company) were used to prepare solutions of $\mathrm{HCl}(1 \mathrm{M})$ and $\mathrm{H}_{2} \mathrm{SO}_{4}(0.5 \mathrm{M})$. The study involved experiments with electrolyte solutions in open air using inhibitor in the concentration range $0-400 \mathrm{ppm}$.

Mild steel coupons for the corrosion tests were carried out using mild steel coupons of composition (\%): 0.089 (C), $0.34(\mathrm{Mn}), 0.037(\mathrm{Cr}), 0.022(\mathrm{Ni}), 0.007(\mathrm{Mo}), 0.005(\mathrm{Cu})$, $0.005(\mathrm{~V}), 0.010(\mathrm{P}), 99.47(\mathrm{Fe})$. For the electrochemical measurements, a $1 \mathrm{~mm}$ thick mild steel sheets were machined in a flag shape, the stem $(\approx 3 \mathrm{~cm})$ of which was covered by araldite paint. The total exposed area was about $2 \mathrm{~cm}^{2}$ (including both side of the surfaces). Emery papers were used to abrade the specimens, which were then washed with acetone and deionized water and then kept in a desiccator.

N,N-Dimethyl-1-dodecylamine (2): A mixture of 1bromodecane $(15 \mathrm{~g}, 60 \mathrm{mmol})$ and dimethylamine 1 (22 $\mathrm{g}$ of $40 \%$ in $\mathrm{H}_{2} \mathrm{O}, 195 \mathrm{mmol}$ ) was stirred at $45^{\circ} \mathrm{C}$ in a closed flask for $36 \mathrm{~h}$, then treated with $\mathrm{NaOH}(2.4 \mathrm{~g}, 60 \mathrm{mmol})$ and extracted with ether $(2 \times 50 \mathrm{~mL})$. After drying over $\mathrm{Na}_{2} \mathrm{SO}_{4}$ and removal of ether, the residue was distilled to get dimethyl compound 2 (colourless liquid, $10.8 \mathrm{~g}, 84.3 \%$ ), bp $\mathrm{bmbarHg}_{413}{ }^{\circ} \mathrm{C}$.

N-Allyl-N,N-dimethyl-1-dodecylammonium chloride (3): Allyl chloride (2.3 g, $30 \mathrm{mmol}$ ) was added to a solution of
N,N-dimethyl-1-dodecylamine (2) $(2.0 \mathrm{~g} ; 9.4 \mathrm{mmol})$ in acetone (2.0 mL) under $\mathrm{N}_{2}$ in a closed flask at $65{ }^{\circ} \mathrm{C}$ for $24 \mathrm{~h}$ to give $\mathbf{3}$ $(2.4 \mathrm{~g} ; 88.3 \%)$ as white crystals (hexane/ether/acetone). m.p. (closed capillary) $81-83^{\circ} \mathrm{C}$; (Found: C, 70.12; H, 12.73; N, 4.68. $\mathrm{C}_{17} \mathrm{H}_{36} \mathrm{NCl}$ requires $\left.\mathrm{C}, 70.43 ; \mathrm{H}, 12.52 ; \mathrm{N}, 4.83 \%\right)$; (KBr, $\left.V_{\max }, \mathrm{cm}^{-1}\right): 3452,2928,2854,1640,1468,1378,1006,960$, 888, 722; $\delta_{\mathrm{H}}\left(\mathrm{CDCl}_{3}\right) 0.88(3 \mathrm{H}, \mathrm{t}, J 7.0), 1.30(18 \mathrm{H}, \mathrm{m}), 1.75$ ( $2 \mathrm{H}, \mathrm{m}), 3.37$ (6 H, s), 3.49 (2 H, app. t, J 8.4 Hz), $4.37(2 \mathrm{H}$, d, J 7.3 Hz), $5.78(2 \mathrm{H}, \mathrm{m}), 5.99(1 \mathrm{H}, \mathrm{m}) ; \delta_{\mathrm{C}} 14.11,22.66$, 22.76, 26.31, 29.21, 29.31, 29.37, 29.44, 29.56 (2C), 31.88, 50.40 (2 C), 63.67, 65.93, 124.58, $129.75\left(\mathrm{CDCl}_{3}\right.$ : 77.25).

N,N-Dimethyl-N-propargyl-1-dodecylammonium chloride (4): Propargyl chloride (1.12 g, $15 \mathrm{mmol}$ ) was added to a solution of $2(2.0 \mathrm{~g} ; 9.4 \mathrm{mmol})$ in acetone $(2.0 \mathrm{~mL})$ under $\mathrm{N}_{2}$ in a closed flask at $52{ }^{\circ} \mathrm{C}$ for $30 \mathrm{~h}$. The resultant salt 4 was purified by crystallization from ether/acetone white crystals, $2.58 \mathrm{~g}, 95.3 \%$ ). m.p. (closed capillary) $100-101^{\circ} \mathrm{C}$; $\left(\mathrm{KBr}, \mathrm{v}_{\max }\right.$, $\left.\mathrm{cm}^{-1}\right)$ : 3444, 3256, 3008, 2920, 2850, 2126, 1468, 1418, 1380, $1002,924,894,722 ; \delta_{\mathrm{H}}\left(\mathrm{CDCl}_{3}\right) 0.88(3 \mathrm{H}, \mathrm{t}, J 6.9 \mathrm{~Hz}), 1.30$ $(18 \mathrm{H}, \mathrm{m}), 1.75(2 \mathrm{H}, \mathrm{m}), 2.99(1 \mathrm{H}, \mathrm{t}, J 2.3 \mathrm{~Hz}), 3.50(6 \mathrm{H}, \mathrm{s})$, $3.64(2 \mathrm{H}$, app. t, $J 8.5 \mathrm{~Hz}), 4.89(2 \mathrm{H}, \mathrm{d}, J 2.3 \mathrm{~Hz}) ; \delta_{\mathrm{C}} 14.13$, 22.69, 22.86, 26.26, 29.17, 29.32, 29.39, 29.46, 29.59 (2 C), 31.91, 50.49 (2 C), 54.26, 63.89, 71.91, $81.15\left(\mathrm{CDCl}_{3}\right.$ : 77.16).

N,N-Diethyl-1-dodecylamine (6): A mixture of 1-bromodecane (7.5 g, $30 \mathrm{mmol})$ and diethylamine $\mathbf{5}$ (11 g, $150 \mathrm{mmol})$ was heated at $60{ }^{\circ} \mathrm{C}$ in a closed vessel for $72 \mathrm{~h}$. Similar workup above procedure gave the diethyl derivative $\mathbf{6}$ as a liquid (5.42 g, $80.2 \%$ ). (Found: C, 79.71; H, 14.48; N, 5.73. $\mathrm{C}_{16} \mathrm{H}_{35} \mathrm{~N}$ requires $\mathrm{C}, 79.59 ; \mathrm{H}, 14.61 ; \mathrm{N}, 5.80 \%$ ); (Neat, $\mathrm{v}_{\max }, \mathrm{cm}^{-1}$ ): 2928, 2854, 2798, 1466, 1380, 1292, 1202, 1070, $722 \mathrm{~cm}^{-1}$; $\delta_{\mathrm{H}}\left(\mathrm{CDCl}_{3}\right) 0.88(3 \mathrm{H}, \mathrm{t}, J 7.0 \mathrm{~Hz}), 1.02(6 \mathrm{H}, \mathrm{t}, J 7.2 \mathrm{~Hz}), 1.26$ $(18 \mathrm{H}, \mathrm{m}), 1.44(2 \mathrm{H}, \mathrm{m}), 2.40$ (2 H, app. t, J 7.9 Hz), 2.51 (4 $\mathrm{H}, \mathrm{q}, J 7.2 \mathrm{~Hz}) ; \delta_{\mathrm{C}} 11.70$ (2 C), 14.13, 22.73, 27.04, 27.80, 29.40, 29.70 (5 C), 31.98, 46.94 (2 C), 53.09 ( $\mathrm{CDCl}_{3}$ : 77.08).

1-Dodecylpyrrolidine (8): To a sample of pyrrolidine 7 (9 g, $127 \mathrm{mmol})$ was added 1-bromodecane (7.5 g, $30 \mathrm{mmol})$ dropwise at $20^{\circ} \mathrm{C}(20 \mathrm{~min})$. The mixture, after heating at $32{ }^{\circ} \mathrm{C}$ for $24 \mathrm{~h}$, was worked up to give the amine $\mathbf{8}$ as a liquid $(6.1 \mathrm{~g}$, $84.9 \%$ ). (Found: $\mathrm{C}, 80.13 ; \mathrm{H}, 13.70 ; \mathrm{N}, 5.75 . \mathrm{C}_{16} \mathrm{H}_{33} \mathrm{~N}$ requires C, 80.26; H, 13.89; N, $5.85 \%$ ); (Neat, $\left.v_{\max }, \mathrm{cm}^{-1}\right)$ : 2924, 2854, $2784,1462,1380,1350,1202,1148,1110,878,722 ; \delta_{\mathrm{H}}$ $\left(\mathrm{CDCl}_{3}\right) 0.88(3 \mathrm{H}, \mathrm{t}, J 7.0 \mathrm{~Hz}), 1.29(18 \mathrm{H}, \mathrm{m}), 1.51(2 \mathrm{H}, \mathrm{m})$, $1.77(4 \mathrm{H}, \mathrm{m}), 2.40(2 \mathrm{H}$, app. t, $J 7.8 \mathrm{~Hz}), 2.47(4 \mathrm{H}, \mathrm{m}) ; \delta_{\mathrm{C}}$ 14.13, 22.73, 23.43 (2 C), 27.84, 29.21, 29.41, 29.70 (4 C), 29.73, 31.97, 54.30 (2 C), $56.81\left(\mathrm{CDCl}_{3}: 77.11\right)$.

Weight-loss measurements: Inhibitor efficiency (IE) was determined by hanging the steel coupon $(2.5 \mathrm{~cm} \times 2.0 \mathrm{~cm} \times$ $0.1 \mathrm{~cm}$ ) into the solutions of the inhibitors (from 0-400 ppm) in $1 \mathrm{M} \mathrm{HCl}(175 \mathrm{~mL})$ containing. At the end, the coupons were washed with water and acetone and finally dried at $110{ }^{\circ} \mathrm{C}$. The following equation was used to calculate the IE (\%):

$$
\mathrm{IE}(\%)=\frac{\mathrm{W}_{\text {blank }}-\mathrm{W}_{\text {inhibitor }}}{\mathrm{W}_{\text {blank }}} \times 100
$$

Triplicate determinations were made for the weight loss in the absence $\left(\mathrm{W}_{\text {blank }}\right)$ and presence of the inhibitor $\left(\mathrm{W}_{\text {initiator }}\right)$. The average IEs were obtained with a standard deviation of $0.2-3.5 \%$. 
Tafel extrapolations: Polarization studies were done in $100 \mathrm{~mL} 1 \mathrm{M} \mathrm{HCl}$ in the presence and absence of the inhibitors. The electrochemical cell in a $250 \mathrm{~mL}$ round bottom flask, consisted of working electrode (mild steel coupon), a graphite rod (5 mm diameter) counter electrode and a reference electrode (saturated calomel electrode, SCE), all of which were connected to a EG\&G PARC potentiostat (Model 283). A sweep of $\pm 250 \mathrm{mV}$ (scan rate of $0.5 \mathrm{mV} / \mathrm{s}$ ) with respect to open circuit potential were applied.

\section{RESULTS AND DISCUSSION}

The new amine derivatives $\mathbf{2}, \mathbf{6}$ and $\mathbf{8}$ were prepared in excellent yields from low-cost materials 1, 5 and $\mathbf{7}$ as shown in Scheme-I. Tertiary amine $\mathbf{2}$ on alkylation with allyl chloride and propargyl chloride afforded the quaternary salts $\mathbf{3}$ and $\mathbf{4}$, respectively. The synthesized compounds were examined as corrosion inhibitors and compared with inhibiting activities of compounds 9-11 [23].

Weight-loss measurements: The weight loss data for inhibition in $1 \mathrm{M} \mathrm{HCl}$ and $0.5 \mathrm{M} \mathrm{H}_{2} \mathrm{SO}_{4}$ are given in Tables 1 and 4 , respectively.
TABLE-1

INHIBITION EFFICIENCY OF AMINE DERIVATIVES FOR MILD STEEL CORROSION IN $1 \mathrm{M} \mathrm{HCl} \mathrm{EXPOSED} \mathrm{FOR} 6 \mathrm{~h}$ AT $60^{\circ} \mathrm{C}$

\begin{tabular}{cccccccc}
\hline & \multicolumn{6}{c}{ Inhibition efficiencies (\%) at } \\
Compd. & \multicolumn{6}{c}{ concentration (ppm) of compounds } \\
\cline { 2 - 8 } & 5 & 10 & 25 & 50 & 100 & 200 & 400 \\
\hline $\mathbf{2}$ & 4.8 & 9.2 & 14 & 65 & 97 & 97 & 98 \\
$\mathbf{3}$ & 9.3 & 20 & 25 & 97 & 98 & 99 & 99 \\
$\mathbf{4}^{\mathbf{b}}$ & 8.8 & 17 & 69 & 94 & 99 & 99 & 99 \\
$\mathbf{6}$ & 5.2 & 10 & 29 & 87 & 99 & 99 & 99 \\
$\mathbf{8}$ & 7.6 & 15 & 33 & 96 & 99 & 99 & 99 \\
$\mathbf{9}^{\text {a }}$ & 6.2 & 12 & 86 & 88 & 98 & 99 & 99 \\
$\mathbf{1 1}$ & 10 & 15 & - & 85 & 94 & 99 & 99 \\
\hline
\end{tabular}

${ }^{\mathrm{a}} 20 \mathrm{ppm}, \mathrm{IE} \% 48 ; 15 \mathrm{ppm}, \mathrm{IE} \% 22 .{ }^{\mathrm{b}} 15 \mathrm{ppm}$, IE \% 43.

The results of the weight loss method in $1 \mathrm{M} \mathrm{HCl}$ at $60{ }^{\circ} \mathrm{C}$ using the new amine derivatives are given in Table- 1 . The results \%IE in $1 \mathrm{M} \mathrm{HCl}$ by the electrochemical method (Table2) supports the results from weight-loss method. All the amines achieved inhibition \% IE of about $99 \%$ in the presence of 200 ppm.<smiles>CNC</smiles>

(1)

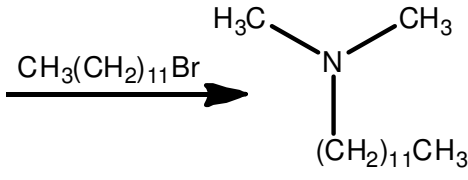

(2)

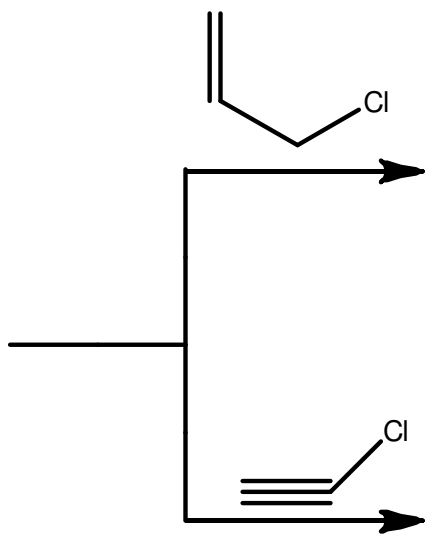<smiles>C=CC[N+](C)(C)[AlH2]C</smiles><smiles>C#C[N+](C)(C)[AlH]C</smiles>

(4)<smiles>C1CCNC1</smiles>

(7)

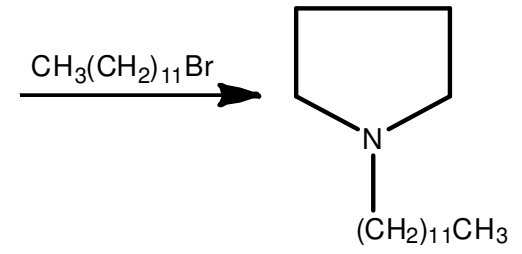

(8)

(6)

Scheme-I: Synthesis of inhibitors 2, 3, 4, 6 and 8

TABLE-2

INHIBITION EFFICIENCIES USING GRAVIMETRIC AND TAFEL PLOTS OF MILD STEEL SAMPLE IN $100 \mathrm{~mL} 1 \mathrm{M} \mathrm{HCl} \mathrm{SOLUTIONS} \mathrm{CONTAINING} 200 \mathrm{ppm}$ INHIBITORS AT $60^{\circ} \mathrm{C}$ FOR $6 \mathrm{~h}$

\begin{tabular}{|c|c|c|c|c|c|c|c|}
\hline Compound & $\begin{array}{c}\mathrm{E}_{\text {corr }} v s . \mathrm{SCE} \\
(\mathrm{mV})\end{array}$ & $\beta_{\mathrm{a}}(\mathrm{V} /$ decade $)$ & $\beta_{\mathrm{c}}(\mathrm{V} / \mathrm{dec}$ ade $)$ & $\mathrm{I}_{\text {corr }}\left(\mathrm{mA} / \mathrm{cm}^{2}\right)$ & $\begin{array}{c}\text { Corr. rate } \\
(\mathrm{mpy})\end{array}$ & Tafel IE & $\begin{array}{c}\text { Gravimetric IE } \\
6 \mathrm{~h}\end{array}$ \\
\hline Blank $\mathrm{HCl}$ & -453 & 0.0599 & 0.1306 & 4.1400 & 1899 & 0 & 0.00 \\
\hline 2 & -478 & 0.1170 & 0.2470 & 0.2446 & 112 & 94.1 & 97.4 \\
\hline 3 & -510 & 0.1090 & 0.1810 & 0.2016 & 92.1 & 95.1 & 98.7 \\
\hline 4 & -458 & 0.0682 & 0.1180 & 0.0328 & 15.0 & 99.2 & 99.0 \\
\hline 6 & -498 & 0.0903 & 0.1830 & 0.2223 & 102 & 94.6 & 98.6 \\
\hline 8 & -490 & 0.1080 & 0.2650 & 0.3196 & 146 & 92.3 & 98.8 \\
\hline 11 & -492 & 0.0923 & 0.1620 & 0.0810 & 37.1 & 98.0 & 98.7 \\
\hline
\end{tabular}


The corrosion current density $\left(i_{\text {corr }}\right)$ has been lowered considerably by the amine derivatives as a result of their inhibitive nature. In the presence of the suggested amines, the corrosion potential $\left(\mathrm{E}_{\text {corr }}\right)$ is shifted in the negative direction in $1 \mathrm{M} \mathrm{HCl}$, thus the cathodic reaction is suppressed.

Polarization curves: Corrosion current density and corrosion potential were obtained from the analysis of the Tafel plots [24]. The results of Tafel plots in $1 \mathrm{M} \mathrm{HCl}$ and $3.5 \% \mathrm{NaCl}$ in the absence and presence of inhibitor molecules at $60{ }^{\circ} \mathrm{C}$ are summarized in Tables 2 and 5, respectively. Table- 2 shows the IEs gravimetric and Tafel plot of mild steel sample in $1 \mathrm{M}$ $\mathrm{HCl}$ solutions in presence and absence of various inhibitors. The results revealed that the corrosion rate decreased in presence of the suggested organo nitrogen compounds, the least corrosion rate occurred in the presence of compound 4 (15\%). The Tafel IE was found to be equal to $99.2 \%$ and the gravimetric IE $(6 \mathrm{~h})$ was $99 \%$. Table- 5 shows the results of Tafel plots of Mild steel in $3.5 \% \mathrm{NaCl}$ solutions in absence and presence of various inhibitors. The lowest rate of corrosive was found in presence of compound $4(15.42 \%)$ as compared to compound $11(24.38 \%)$ and Tafel IE was found to be equal to $85 \%$, as compared to compound $\mathbf{1 1}(70 \%)$.

Adsorption isotherms: Surface coverage is represented by $\theta$, which is known as fractional inhibition efficiency. The $\theta$ values obtained from for the inhibitor molecules are given in the Table- 1 . The $\theta$ values and $\mathrm{C}(\mathrm{mol} / \mathrm{L})$ were utilized to find the suitable isotherm models among Temkin, Langmuir, Frumkin $\left(\mathrm{K}_{\mathrm{ads}} \mathrm{C}=\theta /(1-\theta) \mathrm{e}^{-2 \mathrm{a} \theta}\right)$ and Freundlich [25].

The data fitted Frumkin isotherm the best as revealed by the correlation coefficient in $1 \mathrm{M} \mathrm{HCl}$. In the equation, $\mathrm{K}_{\mathrm{ads}}$ and ' $\mathrm{a}$ ' represent the equilibrium constant and attraction constant, respectively. The $\mathrm{K}_{\mathrm{ads}}$ is related to the free energy of adsorption $\left(\Delta \mathrm{G}_{\text {ads }}^{\mathrm{o}}\right)$, by:

$$
\mathrm{K}_{\mathrm{ads}}=\frac{1}{55.5} \mathrm{e}^{\frac{-\Delta \mathrm{G}_{\mathrm{ads}}^{\mathrm{o}}}{\mathrm{RT}}}
$$

The $\mathrm{K}_{\mathrm{ads}}$ and $\Delta \mathrm{G}_{\text {ads }}^{\mathrm{o}}$ are summarized in Table-3. Adsorption isotherms for some of the molecules are shown in Fig. 1. The negative values of $\Delta \mathrm{G}_{\text {ads }}^{\mathrm{a}}$ (Table-3) and high values for the $\mathrm{K}_{\mathrm{ads}}$ ensure the favourable adsorption on the steel surface in $1 \mathrm{M} \mathrm{HCl}$. Generally, values of $\Delta \mathrm{G}^{\mathrm{o}}$ ads more negative than -20 $\mathrm{kJ} / \mathrm{mol}$ are consistent with a mixture of both physisorption and chemisorption process [26].

Moreover, the inhibition examination in $0.5 \mathrm{M} \mathrm{H}_{2} \mathrm{SO}_{4}$ showed a great deal of satisfaction that the suggested compounds performed very well as inhibitors (Table-4). The amine derivatives imparted good to excellent inhibition efficiency in both

TABLE-3

$\mathrm{K}_{\mathrm{ads}}$, a AND $\Delta \mathrm{G}_{\text {ads }}^{\mathrm{o}}$ FOR THE ADSORPTION OF INHIBITORS AT $60{ }^{\circ} \mathrm{C}$ IN $1 \mathrm{M} \mathrm{HCl}$ USING FRUMKIN ISOTHERM

\begin{tabular}{ccccc}
\hline Compd. & $\mathrm{R}^{2}$ & $\mathrm{a}$ & $\mathrm{K}_{\mathrm{ads}}$ & $\begin{array}{c}\Delta \mathrm{G}_{\text {ads }}^{\mathrm{o}} \\
(\mathrm{kJ} / \mathrm{mol})\end{array}$ \\
\hline $\mathbf{2}$ & 0.9325 & 2.00 & 997 & -30.2 \\
$\mathbf{3}$ & 0.9266 & 2.10 & 2654 & -32.9 \\
$\mathbf{4}$ & 0.9771 & 1.58 & 3707 & -33.9 \\
$\mathbf{6}$ & 0.9904 & 1.65 & 1762 & -31.8 \\
$\mathbf{8}$ & 0.9506 & 2.02 & 2143 & -32.4 \\
$\mathbf{9}$ & 0.9959 & 2.00 & 2263 & -32.5 \\
\hline
\end{tabular}

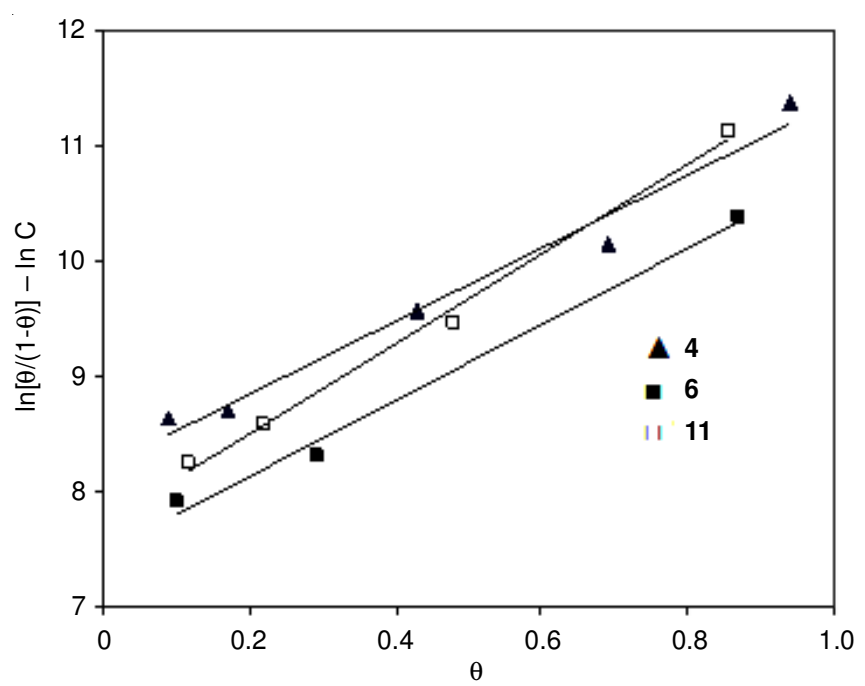

Fig. 1. Frumkin adsorption isotherms of $\mathbf{4 , 6}$ and $\mathbf{1 1}$ in $1 \mathrm{M} \mathrm{HCl}$ at $60{ }^{\circ} \mathrm{C}$

TABLE-4

\begin{tabular}{|c|c|c|}
\hline \multicolumn{3}{|c|}{$\begin{array}{c}\text { TABLE-4 } \\
\text { INHIBITION EFFICIENCY (IE, \%) FOR DIFFERENT } \\
\text { CONCENTRATIONS OF INHIBITORS FOR THE } \\
\text { INHIBITION OF CORROSION OF MILD STEEL } \\
\text { IN } 0.5 \mathrm{M} \mathrm{H}_{2} \mathrm{SO}_{4} \text { EXPOSED FOR } 6 \mathrm{~h} \text { AT } 60^{\circ} \mathrm{C}\end{array}$} \\
\hline \multirow[t]{2}{*}{ Compounds } & \multicolumn{2}{|c|}{$\begin{array}{c}\text { Inhibition efficiencies }(\%) \text { at } \\
\text { concentration }(\mathrm{ppm}) \text { of compounds }\end{array}$} \\
\hline & 100 & 400 \\
\hline 2 & 4.5 & 11 \\
\hline 3 & 1.0 & 24 \\
\hline 4 & 10 & 41 \\
\hline 6 & 1.6 & 2.3 \\
\hline 8 & 58 & 74 \\
\hline 9 & 65 & 80 \\
\hline 10 & 89 & 97 \\
\hline 11 & 36 & 89 \\
\hline
\end{tabular}

$\mathrm{HCl}$ and $\mathrm{H}_{2} \mathrm{SO}_{4}$ media. Tertiary amines 9-11 (possessing diallyl moiety) performed excellent inhibition efficiency, emphasizing the incorporation of $\pi$ electrons with the vacant iron $d$-orbitals to form a protective layer.<smiles>C=CCN(C)CCCC</smiles>

(9)

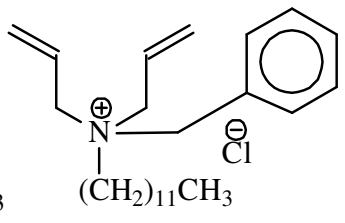

(10)

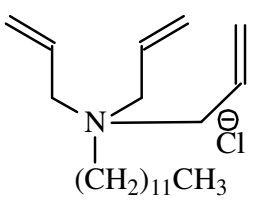

(11)
The results (Table-2) also revealed that the lowest corrosion rate was observed in presence of compound 4 (15.0\%). This compound possesses an electron density ( $\pi$ bond) group as well as long chain hydrocarbon.

This compound exhibited a triple action in suppressing the corrosion rate. First, the long chain hydrocarbon, which would wrap the surface of the metal with hydrophobic layer; thus protecting it from the water molecules. Second, the alkyne group which would perform a covalent bond joining the iron atom as well as possessing the ability to add HCI molecules as shown in Scheme-II. Moreover, compound $\mathbf{1 1}$ also exhibited an excellent suppression corrosion rate (37.1\%). 


\section{TABLE-5}

RESULTS OF TAFEL PLOTS OF MILD STEEL SAMPLE IN VARIOUS SOLUTIONS CONTAINING $200 \mathrm{ppm}$ OF THE INHIBITORS IN $3.5 \% \mathrm{NaCl}$ AT $60{ }^{\circ} \mathrm{C}$

\begin{tabular}{ccccccc}
\hline Compound & $\mathrm{E}_{\text {corr }} v$ s. SCE $(\mathrm{mV})$ & $\beta_{\mathrm{a}}(\mathrm{V} /$ decade $)$ & $\beta_{\mathrm{c}}(\mathrm{V} /$ decade $)$ & $\mathrm{i}_{\text {corr }}\left(\mathrm{mA} / \mathrm{cm}^{2}\right)$ & Corr. rate $(\mathrm{mpy})$ & Tafel IE \\
\hline Blank $\mathrm{NaCl}$ & -659 & 0.0727 & 0.3758 & 0.1748 & 80.18 & 00 \\
$\mathbf{3}$ & -710 & 0.0340 & 0.4725 & 0.0747 & 34.29 & 63 \\
$\mathbf{4}$ & -682 & 0.0357 & 0.1655 & 0.0336 & 15.42 & 85 \\
$\mathbf{1 1}$ & -600 & 0.0367 & 0.0768 & 0.0531 & 24.38 & 70 \\
\hline
\end{tabular}

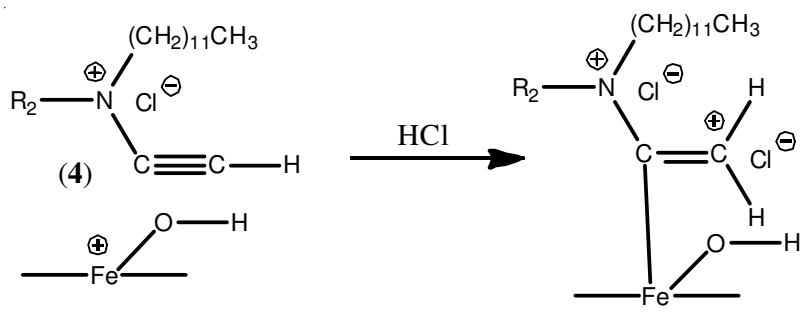

Scheme-II: Corrosion suspension effect of compound $\mathbf{4}$ on mild steel sample in presence of $1 \mathrm{M} \mathrm{HCl}$ solutions

This compound exhibits in its structure allyl electron density bonds as well as the long chain organic hydrocarbon. Its suggested action as metal protective agent is shown in Scheme-III.

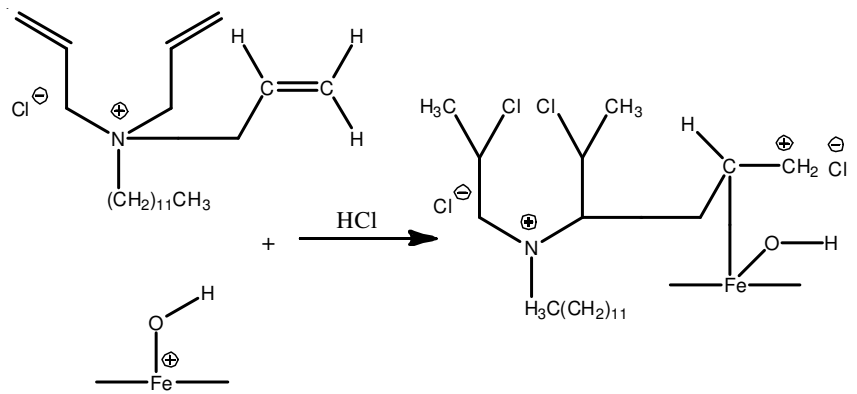

Scheme-III: Corrosion suspension effect of compound $\mathbf{1 1}$ on mild steel sample in presence of $1 \mathrm{M} \mathrm{HCl}$ solutions

Compound 11 exhibits long chain tail of hydrophobic nature capable to keep the steel away from water molecules by wrapping around its exposed surface.

Moreover, the suggested inhibitor 11 structure possesses three allyl bonds acting as electron density power bank. These allyl bonds could either form a bond with iron, removing the positive charge on it or add HCI molecules (Scheme-III).

Conversely, Compound 9 exhibiting only two allyl bonds, showed as good corrosion inhibition (rate $=59.8 \%$ ) but less than that of compound $\mathbf{1 1}$ which exhibited three allylic bonds showing a direct conclusion of the effective action of the electron density of allyl bond in the inhibition process (Scheme-IV).

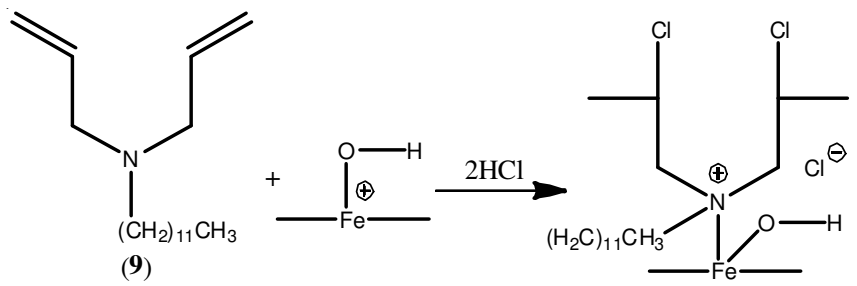

Scheme-IV: Corrosion suspension effect of compound $\mathbf{9}$ on mild steel sample in presence of $1 \mathrm{M} \mathrm{HCl}$ solutions
The lack of any electron density groups in compound $\mathbf{8}$, make it less effective towards the inhibition process, although it exhibits the long chain hydrophobic chain. The inhibition efficiency in this case is supposed to be physical protection; no chemical bond would be formed as shown in Scheme-V.
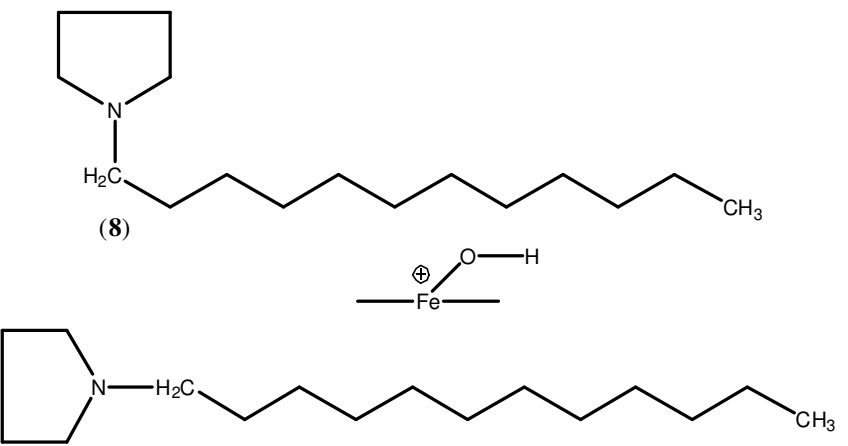

Scheme-V: Corrosion suspension effect of compound $\mathbf{8}$ on mild steel sample in presence of $1 \mathrm{M} \mathrm{HCl}$ solutions

\section{Conclusion}

Some dodecylamine derivatives were found to exhibit excellent inhibition of mild steel corrosion in both the acidic media $\mathrm{HCl}$ and $\mathrm{H}_{2} \mathrm{SO}_{4}$. The $\Delta \mathrm{G}_{\text {ads }}^{\mathrm{o}}$ values indicate the adsorption process as a combination of both physisorption and chemisorption of the inhibitors in $\mathrm{HCl}$ medium. The diallyl moiety in some amine derivatives gives the inhibitors additional ability to protect mild steel corrosion in $0.5 \mathrm{M} \mathrm{H}_{2} \mathrm{SO}_{4}$ where the $\pi$ electrons form coordinate bonds with the iron $d$-orbitals.

\section{ACKNOWLEDGEMENTS}

The author thanks her B.Sc. Students, Sarah Alrasheed and Bayan Al Ghanam for their help. This work was supported in part under the financial Assistant of King Abdul-Aziz City of Science and Technology.

\section{REFERENCES}

1. V.S. Sastri, Corrosion Inhibitors, Principles and Application, John Wiley \& Sons (1998).

2. V.S. Sastri, G.R. Honey and R.W. Review, J. CIM Bull., 87, 87 (1994).

3. S.A. Bradford, Corrosion Control, Van Nostrand Reinhold, New York (1993).

4. L.I. Antropov, Proceedings of 1st International Congress on Metallic Corrosion, Butterworths, London, p. 147 (1962).

5. I.L. Rozenfeld, Corrosion Inhibitors, McGraw-Hill, New York, p. 109(1981).

6. N. Hackerman and R.M. Hurd, Proceedings of International Congress of Metallic Corrosion, Butterworths, London, p. 166 (1962).

7. R.G. Pearson, J. Chem. Educ., 45, 581 (1968); https://doi.org/10.1021/ed045p581.

8. V.S. Sastri and P.R. Roberge, Proceedings of 11 th International Congress, Florence, Italy, vol. 3, p. 55 (1990). 
9. K.Aramaki, T. Mochizuki and H. Nishihara, Proceedings of 10th International Congress on Metallic Corrosion, New Delhi, India, Oxford \& IBH Pub. Co., p. 2759 (1987).

10. S.N. Raicheva, B.V. Aleksiev and E.I. Sokolova, J. Corros. Sci., 34, 343 (1993);

https://doi.org/10.1016/0010-938X(93)90011-5.

11. W. Review and H. Uhlig, Corrosion and Corrosion Control: An Introduction to Corrosion Science and Engineering, Wiley-Interscience, New York (2008).

12. M. ElAchouri, S. Kertit, H.M. Gouttaya, B. Nciri, Y. Bensouda, L. Perez, M.R. Infante and K. ElKacemi, J. Prog. Org. Coating, 43, 267 (2001); https://doi.org/10.1016/S0300-9440(01)00208-9.

13. A. Cizek, Mater. Perform., 33, 56 (1994).

14. W. Frenier and F.B. Growcock, eds.: A. Raman and P. Labine, Review on Corrosion Science and Technology, Houston, TX: NACE International, pp. 11-201 (1993)

15. S. Muralidharan, K.L.N. Phani, S. Pitchumani, S. Ravichandran and S.V.K. Iyer, J. Electrochem. Soc., 142, 1478 (1995); https://doi.org/10.1149/1.2048599.

16. N. Hackerman and R.M. Hurd, 'Proceedings of the International Congress of Metallic Corrosion', Butterworth, London, p.166 (1962)

17. F.B. Growcock, W.W. Frenier and V.R. Lopp, eds.: N.S. Ferrara and V. Sez, Proceedings of 6th European Symposium on Corrosion Inhibitors, Ann. Univ., Suppl. no. 7, p. 1185 (1980).
18. D. Jayaperumal, S. Muralidharan, P. Subramanian, G. Venkatachari and S. Senthilvel, Anti-Corros. Methods Mater., 44, 265 (1997); https://doi.org/10.1108/00035599710183234.

19. J.O.M. Bockris, J. Electrochem. Soc., 138, 2237 (1991); https://doi.org/10.1149/1.2085956.

20. S. Rengamani, S. Muralidharan, M.A. Kulandainathan and S.V. Iyer, J. Appl. Electrochem., 24, 355 (1994) https://doi.org/10.1007/BF00242066.

21. A.M.S. Abdennabi, A.I. Abdulhadi, S.T. Abu-Orabi and H. Saricimen, J. Corros. Sci., 38, 1791 (1996); https://doi.org/10.1016/S0010-938X(96)00087-X.

22. A.E. Stoyanova, E.I. Sokolova and S.N. Raicheva, J. Corros. Sci., 39, 1595 (1997); https://doi.org/10.1016/S0010-938X(97)00063-2.

23. S.A. Ali, S.M.J. Zaidi, A.M.Z. El-Sharif and A.A. Al-Taq, Polym. Bull., 69, 491 (2012); https://doi.org/10.1007/s00289-012-0765-3.

24. S.A. Ali, A.M. El-Shareef, R.F. Al-Ghamdi and M.T. Saeed, J. Corros. Sci., 47, 2659 (2005); https://doi.org/10.1016/j.corsci.2004.11.007.

25. A.N. Frumkin, Z. Phys. Chem., 116, 466 (1925).

26. S.Z. Duan and Y.L. Tao, Interface Chemistry, Higher Education Press, Beijing, pp. 124 (1990) 